\title{
PERANAN CUSTOMER SERVICE DALAM MENINGKATKAN PELAYANAN TERHADAP NASABAH DI PT PT. BTPN PURNA BAKTI KC PADANG
}

\author{
Okvela Sapitri ${ }^{1)}$, Muhammad Hendra ${ }^{2)}$ \\ ${ }^{1,2)}$ Akademi Keuangan dan Perbankan "Pembangunan" AKBP Padang \\ okvelasapitri257@gmail.com
}

\begin{abstract}
The purpose of this study was to determine how the role of customer service in providing services to customers at PT. BTPN Purna Bakti KC Padang. This research method uses descriptive research analysis that is to provide a clear picture of the role of customer service in improving services to customers at PT. BTPN Purna Bakti KC Padang. The results of the study indicate that customer service is very useful for improving services as well as efforts to promote the good image of PT. BTPN Purna Bakti KC Padang is the receptionist, deksman, salesman, customer relations officer and as commiunicator.
\end{abstract}

Keywords: Customer Service, service.

\section{PENDAHULUAN}

Saat ini kemajuan dunia usaha sangat pesat di berbagai sektor, termasuk sektor perbankan di Kota Padang yang semakin hari semakin kompetitif. Perkembangan ini berbagai kemudahan yang diberikan oleh pemerintah demi menopang perkembangan dunia usaha tersebut. Salah satu dengan adanya menciptakan cara atau suasana yang baik bagi perkembangan usaha dibidang yang membuka kantor cabang di Sumatera Barat, terutama di Kota Padang.

Perbankan merupakan suatu institusi yang memiliki peranan strategis didalam berbagai bidang, baik itu pada kegiatan masyarakat khususnya di bidang keuangan (financial), dan kegiatan ekonomi demi memberi kebutuhan pribadi seseorang (Hakim, 2018). Banyaknya bank yang terdiri di Indonesia ini, memuat kompetisi semakin teliti dan bersaing untuk mendapatkan peringkat paling baik dimata masyarakat, khususnya di Kota Padang. Oleh sebab itu, diperlukan prosedur yang efektif masing-masing bank guna untuk meningkatkan laba dan mempunyai kualitas yang baik.

Dengan adanya peranan customer service dalam meningkatkan pelayanan terhadap nasabah di bank atau di instasi lain, karena pelayanan yang efektif merupakan kunci sukses dan dasar untuk membangun keberhasilan di suatu perusahaan. Setiap bank mempekerjakan petugas pelayanan pelanggan (customer service) dalam memberikan pelayanan yang efektif dan menyenangkan hati terhadap nasabah, karena peranan customer service sangat bermakna dan merupakan tulang punggung aktivitas operasional dalam dunia perbankan. Tanpa adanya peranan customer service maka sangat berpengaruh atas perkembangan bank. 
Customer service adalah orang yang dijumpai oleh nasabah ketika ia melakukan ikatan dengan bank dalam membantu membuka rekening dan mencetak buku tabungan nasabah serta membagi kepuasan dalam memberi kebutuhan dan harapan nasabah (Imelda, 2017). Oleh sebab itu, seorang customer service diharuskan mempunyai keahlian yang tepat dan cepat tanggap dalam melayani seorang pelanggan (nasabah) sehingga dapat mengupayakan pelayanan yang terbaik untuk kepuasan dalam mengurus berbagai macam keperluan seorang pelanggan (Sheila Almira, 2020).

Massie \& Soegoto, (2015) mendefenisikan pelayanan adalah aktivitas ekonomi yang membentuk dan memberikan keuntungan bagi pelanggan pada waktu tertentu, sebagai hasil dan kegiatan melaksanakan perubahan yang diinginkan dalam diri atau atas nama penerima jasa tersebut. Pelayanan menjadi sangat penting bagi setiap perusahaan untuk berkembang, termasuk pula kepada badan usaha perbankan karena pelayanan sangat berkaitan erat dengan sumber daya manusia di dalamnya. Oleh karena itu, pihak bank perlu mendefenisikan dengan jelas peringkat pelayanan yang disediakan yang harus mereka berikan dan supaya para nasabah mengetahui juga apa yang mereka peroleh (Fernandes \& Marlius, 2018).

Pelayanan yang diberikan customer service tidak hanya sekedar melayani, melainkan bagaimana menciptakan pelanggan merasa percaya dan puas dengan pelayanan yang diberikan. Karena kepercayaan dan kepuasan pelanggan akan membentuk kerjasama antara bank dengan pelanggan yang berpendapat untuk memperoleh keberhasilan bank. Agar terciptanya kepercayaan, kenyaman, dan kepuasan pelanggan terhadap bank diperlukan pelayanan customer service yang maksimal.

Dalam memberikan pelayanan, customer service selalu mengusahakan upaya mampu menyenangkan hati nasabah tanpa adanya melanggar etika atau harga diri. Dengan adanya pelayanan yang efektif membuat nasabah merasa nyaman dan dihargai sebagai pihak yang membutuhkan jasa, sehingga nasabah akan kembali lagi mendatangi bank tersebut serta akan berbagi cerita dengan rekan yang lainnya.

Dalam kegiatan operasionalnya, PT. BTPN Purna Bakti KC Padang hendaknya memiliki sumber daya yang diharapkan mampu menjalankan fungsi sebagai Resepsionis, Deskman, Salesman, Customer Relation Officer, dan Komunikator. Sumber daya dimaksud yaitu customer service tak hanya dibutuhkan, serta seorang customer service yang profesional karena peranan customer service sangat berguna untuk meningkatkan pelayanan juga upaya mempromosikan citra baik PT. BTPN Purna Bakti KC Padang. Oleh karena itu, customer service mesti harus memiliki keahlian berkomunikasi yang baik melalui dengan tersedianya perlengkapan yang membantu kecepatan, ketetapan, dan keakuratan aktivitas sehingga bisa memberikan pelayanan yang efektif bagi kepuasan nasabah. 
Tabel 1

Jumlah Nasabah Pembukaan Rekening di PT. BTPN Purna Bakti KC Padang

\begin{tabular}{cc}
\hline Tahun & Jumlah Nasabah \\
\hline 2018 & 310 orang \\
2019 & 395 orang \\
2020 & 208 orang \\
Jumlah & 913 orang \\
\hline
\end{tabular}

Sumber: PT. BTPN Purna Bakti KC Padang

Berdasarkan tabel diatas, dapat kita lihat bahwa jumlah nasabah yang membuka rekening pada PT. BTPN Purna Bakti KC Padang tahun 2018 - 2020 berfluktuasi (meningkat dan menurun). Yang mana pada tahun 2018 jumlah nasabah yang membuka rekening sebanyak 310 orang, pada tahun 2019 jumlah nasabah yang membuka rekening meningkat yaitu sebanyak 395 orang, sedangkan pada tahun 2020 nasabah yang membuka rekening menurun yaitu sebanyak 208 orang. Hal ini sebabkan karena Pandemi Covid-19 yang melanda di Indonesia.

PT. BTPN Purna Bakti KC Padang merupakan salah satu unit Perbankan di Kota Padang yang telah berusaha membagikan pelayanan yang efektif dalam melayani nasabahnya. Maka penulis tertarik untuk membahas dan menuangkannya dalam bentuk Tugas Akhir yang diberi judul "Peranan Customer Service Dalam Meningkatkan Pelayanan Terhadap Nasabah Di PT. BTPN Purna Bakti KC Padang".

\section{METODE PENELITIAN}

Metode penelitian yang digunakan: 1) Studi Perpustakaan (library research), yaitu pada penelitian ini dilakukan dengan mengumpulkan data dan menggunakan teori-teori yang berkaitan dengan masalah-masalah yang dibahas. 2) Studi Lapangan (field research), yaitu pada penelitian ini dilakukan dengan cara melakukan pengamatan langsung dan melakukan wawancara dengan pihakpihak yang terkait.

Untuk menganalisa data penelitian, penulis menggunakan analisa deskriptif yaitu memberikan gambaran yang jelas tentang peranan customer service dalam meningkatkan pelayanan terhadap nasabah di PT. BTPN Purna Bakti KC Padang.

\section{HASIL DAN PEMBAHASAN Pengertian Bank}

Bagi masyarakat umum masih banyak berpendapat bahwa bank menjadi tempat untuk menyimpan dan meminjam uang. Faktanya bank banyak mempromosikan jasa-jasa lainnya, juga menawarkan jasa simpanan dan pinjaman/kredit. Berbeda dengan orang yang benar paham tentang perbankan dalam menjelaskan pemahaman bank itu sendiri (Nazrian \& Hidayat, 2012).

Bank adalah lembaga keuangan yang fungsi utamanya adalah menghimpun dana dari masyarakat dan menyalurkannya kepada masyarakat, dan juga memberikan pelayanan dalam bentuk jasa-jasa perbankan. 
Bank mempunyai usaha pokok yang berbentuk menghimpun dana dari pihak yang berlebihan dana dan kemudian menyalurkan kembali dana tersebut ke masyarakat yang kekurangan dana dalam jangka waktu tertentu.

\section{Fungsi Bank}

Fungsi utama bank adalah menghimpun dana dari masyarakat dan menyalurkannya kembali kepada masyarakat untuk berbagai tujuan atau sebagai financial intermediary (perantara keuangan). Menurut Totok Budisantoso, (2018) secara spesifik bank dapat berfungsi sebagai:

a. Agent of trust, yaitu sebagai lembaga yang dasarnya adalah kepercayaan.

b. Agent of development, yaitu lembaga yang mengumpulkan dana untuk membangun ekonomi.

c. Agent of services, yaitu lembaga yang memberikan jasa perbankan yang lain untuk masyarakat.

\section{Jenis-jenis Bank}

Terdapat beberapa jenis perbankan Indonesia yang diatur dalam UndangUndang Perbankan. Menurut Kasmir, (2013) jenis bank bermacam-macam terkait dengan cara pengelompokannya yaitu berdasakan hal-hal sebagai berikut:

a. Jenis Bank Berdasarkan Fungsinya

Pengertian bank umum dan bank perkreditan rakyat sesuai dengan Undang-Undang No. 10 Tahun 1998, adalah sebagai berikut:

1) Bank Umum

Menurut Undang-Undang RI No. 10 Tahun 1998 tentang Perbankan menyatakan "Bank Umum adalah bank yang melakukan aktivitas usaha sebagai konvensional dana atau berdasarkan prinsip syariah yang pada aktivitasnya memiliki jasa pada lalu lintas pembayaran".

2) Bank Perkreditan Rakyat (BPR)

Menurut Undang-Undang RI No. 10 Tahun 1998 Bank Perkreditan Rakyat (BPR) adalah bank yang melancarkan aktivitas usaha sebagai konvensional atau berdasarkan prinsip syariah yang pada aktivitasnya tidak memberikan jasa pada lalu lintas pembayaran.

b. Jenis Bank Berdasarkan Kepemilikannya

1) Bank Milik Pemerintah

Bank milik pemerintah adalah bank yang semua atau setengah dananya dan sertifikat pembentukannya didirikan oleh pemerintah.

2) Bank Milik Swasta Nasional

Bank milik swasta adalah bank yang semua atau setengah dananya dan sertifikat pembentukannya didirikan oleh swasta.

3) Bank Milik Koperasi

Kepemilikan jasa-jasa bank ini yang dihasil oleh perusahaan yang berbadan hukum koperasi.

4) Bank Milik Asing

Bank jenis ini merupakan cabang dari bank yang terdapat diluar negeri, baik itu milik swasta asing maupun pemerintah asing. Karena pemiliknya jelas dimiliki oleh pihak luar negeri.

5) Bank Milik Campuran 
Kepemilikan jasa bank campuran diterima oleh pihak asing dan pihak swasta nasional. Karena kepemilikan jasanya sebagian besar dipegang oleh warga negara Indonesia.

c. Jenis Bank Berdasarkan Segi Status

1) Bank Devisa

Bank devisa adalah bank yang mampu menyelenggarakan aktivitas usaha sebagai konvensional dana atau berlandaskan prinsip syariah yang bisa memberikan pelayanan lalu lintas pembayaran dalam luar negeri yang sudah mendapat persetujuan dari Bank Indonesia.

2) Bank Non Devisa

Bank non devisa adalah bank yang belum mendapat persetujuan dari Bank Indonesia untuk membagikan pelayanan lalu lintas pembayaran dalam dan luar negeri seperti bank devisa.

d. Jenis Bank Berdasarkan Cara Menentukan Harga

1) Bank Berdasarkan Prinsip Konvensional

Bank yang berdasarkan prinsip konvensional menentukan bunga seperti harga dan menggunakan biaya dalam nominal atau bagian tertentu dalam memperoleh laba dan memilih harga produk bank.

2) Bank Berdasarkan Prinsip Syariah

Bank berdasarkan prinsip syariah yang memakai aturan kesepakatan menurut hukum islam pada pembiayaan berlandaskan prinsip bagi hasil (mudharabah), pembiayaan berlandaskan penyertaan modal (musharakah), pembiayaan barang modal berlandaskan sewa murni tanpa pilihan (ijarah) atau adanya pilihan pemindahan kepemilikan atas barang yang disewakan dari pihak bank oleh pihak lain (ijarah wa iqtina).

\section{Pengertian Customer Service}

Pelayanan nasabah atau customer service pada sebuah bank merupakan pelayanan yang diberikan oleh bank pada nasabah untuk masyarakat pada umumnya yang berkaitan dengan aktivitas usaha dan operasional bank sehari-hari. Terjadinya persaingan antarbank yang semakin selektif seperti sekarang ini, sebagian nasabah berkeinginan mendapatkan pelayanan yang efektif dari bank melewati kemudahan berasosialisasi dengan bank, pelayanan yang cepat, dan keramahan petugas bank baik dari segi jasa atau produk yang bertransaksi maupun persoalan pelayanan yang diberikan kepada nasabah.

Pengertian customer service adalah suatu pelayanan untuk menangani bentuk informasi, keluhan, pendapat dan nasehat yang datang dari bank (Lumbantobing, 2015). Seorang customer service bertugas melayani, membagi informasi tentang produk-produk bank dan fasilitas-fasilitas apa saja yang dipunyai oleh bank serta membentuk hubungan yang sesuai dengan para nasabah atau calon nasabah (Hariyanti, 2013).

Customer service memiliki peranan sangat berguna memberikan pelayanan dan dituntut untuk selalu berasosialisasi dengan nasabah dan memelihara hubungan itu tetap baik. Perihal ini perlu dilakukan karena menjaga hubungan 
yang baik dengan nasabah berarti menjaga image bank agar penilaian bank dapat berkembang atau meningkat di mata nasabah. Customer service bank saat melayani para nasabah harus mempunyai keahlian dalam melayani nasabah secara tetap dan cepat dan mempunyai keahlian dalam berhubungan yang efektif dengan diikuti tersedianya sarana dan prasarana yang membantu kelancaran, ketetapan, dan keakuratan kegiatan. Karena customer service merupakan pintu utama sebuah bank.

\section{Pengertian Nasabah}

Nasabah adalah konsumen (customer) yaitu perseorangan yang memperoleh keuntungan produk dan jasa dari sebuah perusahaan perbankan, meliputi aktivitas pembelian, penyewaan dan layanan jasa (Nasution \& Sutisna, 2015). Nasabah memiliki posisi yang berguna dalam dunia perbankan, karena dana yang disimpan nasabah di bank menjadi dana yang pertama dalam operasional bank untuk melaksanakan usahanya.

Bank harus bisa menyakin nasabah untuk menyimpan dananya, agar bersedia menyimpan dana di bank. Hingga pihak bank memberikan kepercayaan berbentuk balas jasa atas si penyimpan (nasabah). Balas jasa tersebut berbentuk memberi hasil, hadiah, bunga, pelayanan atau balas jasa lainnya. Semakin banyak balas jasa yang diberikan, maka akan bertambah minat masyarakat atau nasabah untuk menyimpan dananya. Oleh sebab itu, pihak bank perlu memberikan kepercayaan maka para nasabah berkeinginan untuk menyimpan dananya.

\section{Pengertian Pelayanan}

Pelayanan adalah aktivitas yang bisa ditawarkan untuk suatu kelompok kepada kelompok lain, pada hakikatnya tidak berbentuk dan tidak mengakibatkan kepemilikan kepada sesuatu yang berhubungan dengan suatu produk materi ataupun tidak (Faroh, 2017).

Pelayanan menjadi sangat berarti bagi setiap perusahaan maupun badan usaha perbankan, karena pelayanan sangat berkaitan dengan sumber daya manusia di dalamnya. Banyak strategi dan sistem yang mengefisienkan untuk membangun sumber daya manusia, agar dapat bekerja dan memperlakukan nasabah dengan efektif. Pelayanan sering pula dijadikan acuan untuk menghitung kepuasan konsumen.

Pelayanan yang diberikan supaya bisa memuaskan nasabah, karena seorang petugas meski mempunyai dasar-dasar pelayanan yang kokoh sesuai etika pelayanan, pemahaman produk dan dasar-dasar pelayanan lainnya. Pelayanan yang diberikan lebih bermutu apabila setiap petugas dibekali pemahaman mengenai dasar-dasar pelayanan yang cocok dengan dibidang pekerjaan yang bakal dihadapinya, tergolong pemahaman dalam mempunyai pengetahuan mengenai segala yang berkaitan dengan perusahaan.

\section{Pembahasan}

Peranan customer service dalam meningkatkan pelayanan terhadap nasabah pada PT. BTPN Purna Bakti KC Padang merupakan kunci dasar dan sukses untuk membentuk keberhasilan bank tersebut. Oleh sebab itu, seluruh kegiatan harus beroperasi dengan efektif dan berkualitas bagi terciptanya kepuasan nasabah. Karena nasabah merasa memperoleh kepuasan akan tiba lagi 
mendatangi bank tersebut dan membeli produk lain yang ditawarkan oleh bank serta akan berbagi cerita dengan nasabah yang lainnya.

Customer service memiliki sasaran untuk menciptakan, memperbaiki, mempertahankan nasabah/pelanggan dengan pelayanan yang berkualitas, ini sangat membantu untuk memperoleh keuntungan bagi bank.

Untuk menjalankan hal tersebut diperlukan sumber daya bank serta langkah-langkah yang perlu dilihat dengan baik. Pelayanan berkualitas yang diberikan bagi seorang customer service akan memberikan kepuasan bagi nasabah, ini merupakan keinginan dari semua yang dibutuhkan bank dalam meningkatkan dan memperoleh tujuan bank tersebut. Pelayanan yang diberikan oleh customer service di PT. BTPN Purna Bakti KC Padang merupakan pelayanan yang bermutu untuk memelihara dan mempertahankan nasabah, supaya nasabah tersebut pasti menjadi nasabah PT. BTPN Purna Bakti KC Padang.

Pelayanan yang bermutu sangat berarti bagi bank, serta nasabah dan bagi staf bank lainnya. Karena bisa menjaga loyalitas nasabah memberikan kombinasi untuk memutuskan ketentuan dan hal membeli dan memastikan produk serta memberikan kebanggan pada bank dan produknya. Pelayanan berkualitas bukan hanya memberikan suatu layanan. Hal ini menggunakan pelayanan yang ekstra dan cocok dengan harapan nasabah yang menginginkan pelayanan yang terbaik.

Selain itu, customer service juga harus melindungi nasabah lama agar senantiasa menjadi nasabah di PT. BTPN Purna Bakti KC Padang. Maka dari itu, customer service merupakan kunci utama pada aktivitas operasional di dunia perbankan di PT. BTPN Purna Bakti KC Padang.

Peranan seorang customer service dalam meningkatkan pelayanan terhadap nasabah di PT. BTPN Purna Bakti KC Padang, dapat dilihat sebagai berikut:

a. Selalu memfokuskan produk-produk yang ada di BTPN.

b. Mengenali seluruh aktivitas yang menjadi kehendak bagi seorang nasabah dan selalu memberikan sikap yang positif.

c. Menolong nasabah dalam membuka dan penutupan rekening.

d. Menjaga nasabah lama lebih konsisten dan setia sebagai nasabah bank dengan ikatan yang lebih dekat dengan nasabah.

e. Selalu berusaha untuk memperoleh nasabah baru, misalnya menyakinkan nasabah tentang kualitas produk yang diberikan oleh BTPN.

Customer service PT. BTPN Purna Bakti KC Padang dalam memberikan pelayanan terhadap nasabah, maka harus memiliki konsisten dalam menjelaskan tugasnya sebagai berikut:

a. Membantu nasabah membuat ATM, membuka rekening simpanan, melaporkan buku tabungan atau ATM hilang, meminta informasi saldo dan transaksi rekening, serta mencetak buku tabungan.

b. Melakukan identifikasi dan membuktikan identitas diri nasabah bagi yang membuka rekening simpanan pada PT. BTPN Purna Bakti KC Padang.

c. Menyiapkan dokumen-dokumen dan warkat-warkat yang berkaitan dengan pembukuan rekening giro, tabungan, deposito atau sertifikat deposito, penerbitan kartu ATM dan lain-lainnya. 
Dalam menangani nasabah, customer service mesti memiliki pengetahuan tentang produk-produk yang ada di bank secara keseluruhan. Hal ini mampu meningkatkan pelayanan dan kepuasan nasabah, agar nasabah akan merasakan keperluannya mampu dilakukan dengan penuh tanggung jawab oleh customer service PT. BTPN Purna Bakti KC Padang.

\section{Fungsi Customer Service Pada PT. BTPN Purna Bakti KC Padang}

Sebagai seorang customer service di PT. BTPN Purna Bakti KC Padang tentu telah ditetapkan fungsi dan tugas yang harus diembannya. Fungsi dan tugas customer service harus benar-benar dipahami sehingga dapat menjalankan tugasnya secara prima.

Dalam praktiknya fungsi customer service di PT. BTPN Purna Bakti KC Padang yaitu:

a. Sebagai Resepsionis

Customer service berfungsi sebagai menyambut tamu (nasabah) yang berkunjung ke BTPN dengan sikap ramah, sopan, dan menyenangkan serta menolong nasabah yang hendak bertemu atau memiliki urusan dengan unit lainnya.

b. Sebagai Deskman

Customer service sebagai orang yang melayani pertanyaan nasabah dan membagikan informasi tentang keunggulan produk atau jasa BTPN, menyiapkan bermacam brosur dan formulir untuk keperluan nasabah serta menolong dan memberikan arahan atau petunjuk tentang cara-cara pengisian aplikasi ataupun prosedur transaksi.

c. Sebagai Salesman

Customer service berfungsi melakukan cross selling terhadap penjualan yang dilakukan, serta customer service melakukan morning call kepada nasabah yang aktif dan jika ada produk terbaru maka customer service akan menawarkan pada nasabah tersebut.

d. Sebagai Customer Relation Officer

Customer service berfungsi sebagai menjaga hubungan yang baik terhadap para nasabah dengan memberikan pelayanan yang terbaik, serta membujuk nasabah agar tetap bertahan di BTPN dan tidak berpindah ke bank lain.

e. Sebagai Komunikator

Customer service berfungsi selalu memberikan atau menjaga sikap sopan, santun dan tetap berlaku sabar dalam menghadapi setiap keluhan dari para nasabah serta menangani keluhan, keberatan dan permasalahan nasabah.

\section{Aktivitas Pembukaan Rekening Oleh Customer Service}

a. Prosedur Pembukaan Tabungan Rekening Pensiun

Untuk memberikan kemudahan kepada nasabah dalam membuka rekening tabungan di PT. BTPN Purna Bakti KC Padang membuat prosedur pembukaan rekening, selain melancarkan para nasabah juga mencegah oknum-oknum yang tidak bertanggung jawab, sehingga dengan adanya prosedur tersebut maka para nasabah akan merasa aman menyimpan uang di bank. 
1) Customer service menjelaskan produk tabungan yang ada di PT. BTPN Purna Bakti KC Padang serta prosedur dan persyaratan pembukaan rekening.

2) Apabila calon nasabah berkeinginan untuk membuka rekening di PT. BTPN Purna Bakti maka customer service akan memberikan formulir pembukaan rekening kepada nasabah.

3) Berdasarkan hal yang bisa dilakukan oleh calon nasabah:

a) Mengisi dan menandatangani formulir pembukaan rekening dengan memberi materai 6.000.

b) Membuat KCTT (Kartu Contoh Tanda Tangan) calon nasabah.

c) Menyiapkan persyaratan pembukaan rekening, seperti fotocopy KTP/SIM/Kartu Identitas lainnya.

4) Customer service akan memeriksa kelengkapan pengisian formulir pembukaan rekening serta formulir data nasabah.

5) Apabila formulir pembukaan rekening dan data nasabah sudah lengkap maka customer service akan menginput data calon nasabah dengan cara membuat laporan pembukaan rekening.

6) Customer service membuka rekening tabungan dengan memanfaatkan sistem, berarti customer service membantu calon nasabah untuk membuka rekening dan memasukan ke dalam sistem yang telah ditetapkan oleh pihak bank.

7) Pengesahan buku tabungan terbagi menjadi 2, yaitu:

a) Memberi cap yang dilakukan oleh customer service.

b) Customer service meminta pengesahan buku tabungan kepada Supervisor (dengan memberikan tandatangan pada buku tabungan).

8) Customer service menyiapkan slip setoran awal (2 rangkap) pada nasabah.

9) Customer service menyerahkan:

a) Buku tabungan (yang telah disahkan).

b) ATM

c) Slip setoran awal.

10) Customer service menyimpan formulir pembukaan rekening serta melaporkan fotocopy identitas nasabah.

11) Sebagai setoran awal yang bisa dilakukan oleh nasabah, diantaranya:

a) Nasabah memasukan slip setoran (2 rangkap).

b) Menyerahkan dana setoran awal pada buku tabungan.

12) Teller menerima, memeriksa dan menghitung setoran awal nasabah.

13) Teller membenarkan slip setoran dan kemudian mencetak buku tabungan (memberikan paraf dan cap tanggal transaksi).

14) Teller menyerahkan buku tabungan serta slip copy setoran kepada nasabah dan slip asli disimpan di Teller.

b. Dokumen yang diperlukan untuk Pembukaan Rekening PT. BTPN Purna Bakti KC Padang

Dokumen-dokumen bank merupakan data catatan atau bukti yang dibuat dan diterima oleh bank dalam bentuk pelaksanaan kegiatannya, baik 
tertulis maupun tidak tertulis. Salah satu dokumen wajib yang dikerjakan dan disimpan oleh bank adalah dokumen pembukaan rekening.

Dokumen yang diperlukan untuk pembukaan rekening di PT. BTP Purna Bakti KC Padang diantaranya:

1) Melengkapi formulir pembukaan rekening

a) Perorangan

Merupakan data-data nasabah yang mengisi identitas nasabah, seperti nama lengkap, alamat/tempat saat ini, ahli waris dan pekerjaan.

b) Non perorangan

Merupakan data-data nama perusahaan/badan/instansi terkait yang berisi nama dan alamat perusahaan beserta direksi/pimpinan/kuasa.

2) Melengkapi dokumen pendukung untuk pembukaan rekening, seperti:

a) Kartu Tanda Penduduk.

b) NPWP.

c) Kartu Keluarga.

d) Menyetorkan dana awal pembukaan rekening.

e) Slip setoran.

Dipergunakan untuk menyetor atau menabung dana tabungan dengan mencantumkan sejumlah nominal yang akan disimpan atau di tabung dan mendatangani slip setoran tersebut.

c. Penutupan Rekening Nasabah

1) Permintaan penutupan rekening yang bisa dilakukan atas permintaan nasabah atau ahli waris (jika pemilik rekening meninggal dunia).

2) Penutupan rekening atas pertimbangan bank dan atau ketentuan dari regulator/pemerintah melalui informasi resmi dapat dilakukan berdasarkan persetujuan tertulis pemimpin yang berhak (sekurangkurangnya pejabat bisnis di level area).

3) Kondisi khusus dana atau atas pertimbangan bank seperti penutupan rekening pasif dengan saldo nihil.

4) Persyaratan dokumen penutupan rekening karena nasabah meninggal dunia, dilakukan oleh ahli waris/kuasa yang sah:

a) Surat keterangan kematian dari instasi yang berwenang.

b) Surat pernyataan ahli waris yang dilegalisir notaris/pengadilan negeri setempat atau sesuai perundang-undangan yang berlaku.

c) Dokumen identitas yang sah dari para ahli waris (KTP/passport dan kartu keluarga/akta kelahiran).

d) Surat kuasa dari para penerima waris kepada pihak yang dikuasakan (jika dikuasakan).

\section{SIMPULAN}

Berdasarkan uraian dan pembahasan yang telah dijelaskan, maka bisa diambil kesimpulan sebagai berikut:

a. Seorang customer service di PT. BTPN Purna Bakti KC Padang tentu telah ditetapkan fungsi dan tugas yang harus diembannya dalam memberikan 
pelayanan kepada nasabah sebagai resepsionis, deksman, salesman, customer relation officer dan sebagai komunikator. Customer service berperan penting untuk meluaskan pelayanan kepada nasabah dengan cara memberikan kemudahan-kemudahan dalam transaksi apa saja yang membutuhkan Customer Service.

b. Dalam melancarkan pembukaan rekening tabungan calon nasabah melengkapi syarat-syarat dan ketentuan, diantaranya:

1) Tabungan dibuka atas nama perorangan atau non perorangan.

2) Setiap nasabah memenuhi kelengkapan.

3) Nasabah harus mencantumkan KCTT.

c. Persyaratn yang diperlukan dalam pembukaan rekening di PT. BTPN Purna Bakti KC Padang, yaitu:

1) Formulir pembukaan rekening yang didalamnya tertera identitas nasabah.

2) KTP

3) NPWP

4) Kartu keluarga.

\section{UCAPAN TERIMA KASIH}

Penulis ucapkan puji dan syukur atas kehadiran Allah SWT, yang telah melimpahkan rahmat dan hidayahnya kepada penulis. Penulis ingin mengucapkan terima kasih kepada PT. BTPN Purna Bakti KC Padang yang telah memberikan motivasi, masukan-masukan yang bermanfaat bagi penulis dan terima kasih untuk teman-teman atas semangat dan dukungannya dalam pembuatan Artikel ini. Akhir kata penulis ucapkan terima kasih. Semoga apa yang penulis tuangkan dalam Artikel ini memberikan manfaat terutama bagi saya sendiri selaku penulis. Aamiin ya Robba'alamin.

\section{DAFTAR PUSTAKA}

Faroh, W. N. (2017). Analisa pengaruh harga, promosi, dan pelayanan terhadap keputusan pembelian. Journal Ilmiah Prodi Manajemen, 4(2), 3-24.

Fernandes, Y. D., \& Marlius, D. (2018). Peranan Customer Service Dalam Meningkatkan Pelayanan Kepada Nasabah Pada PT. Bank Pembangunan Daerah Sumatera Barat Cabang Utama Padang. https://doi.org/10.31227/osf.io/wrh3p

Hakim, L. dan O. E. T. (2018). Prinsip Kehati-Hatian Pada Lembaga Perbankan Dalam Pemberian Kredit. Jurnal Keadilan Progresif, 9(2).

Hariyanti, P. R. U. (2013). Pengaruh Aktivitas Customer Service dan Kepuasan Nasabah terhadap Loyalitas Nasabah Bank Riau Kepri Capem Panam Pekanbaru. Jurnal Komunikasi, 8(1), 63-78.

Imelda, S. (2017). Kualitas Pelayanan Customer Service Dan Loyalitas Nasabah Pada Bank Bri Unit Veteran Banjarmasin. Jurnal INTEKNA : Informasi Teknik Dan Niaga, 17(1), 79-147. 
https://doi.org/10.31961/intekna.v17i2.469

Kasmir, D. (2013). Bank dan Lembaga Keuangan Lainnya. Jakarta: PT. RajaGrafindo Persada.

Lumbantobing, V. M. (2015). Peranan Komunikasi Customer Service terhadap Kepuasan Pelanggan Lintas Semesta Surabaya. Jurnal Komunikasi, 9(1), 13-20. https://journal.trunojoyo.ac.id/komunikasi/article/view/1148

Marlius, D., \& Nurfazila, N. (2020). Aktivitas Pemasaran Tabungan Pada Pt. Bank Pembangunan Daerah Sumatera Barat Cabang Pembantu Tarusan. https://doi.org/10.31219/osf.io/fvqc7

Massie, V. R. B. J. D. ., \& Soegoto, A. S. (2015). Peran Pelayanan Teller Dan Costumer Service Terhadap Kepuasan Pelanggan Pada Bank BRI Unit Karomabasan Cabang Manado The Role Of Teller And Customer Service To Customer Satisfication Of Bank BRI Unit Karombosan Branch Manado. Jurnal EMBA, 3(3), 1126-1139.

Nasution, M. H., \& Sutisna, S. (2015). Faktor-Faktor Yang Mempengaruhi Minat Nasabah Terhadap Internet Banking. Nisbah: Jurnal Perbankan Syariah, 1(1), 62. https://doi.org/10.30997/jn.v1i1.241

Natasya, P., \& Marlius, D. (2021). Peranan Customer Service Dalam Meningkatkan Pelayanan Kepada Nasabah Pada PT. BPD Sumatera Barat Cabang Pasar Raya Padang. https://doi.org/10.31219/osf.io/4y6g8

Nazrian, A., \& Hidayat, P. (2012). Studi Tentang Keputusan Nasabah Dalam Menabung Di Bank Sumut Cabang Usu Medan Metode Analytical Hierarchy Process (Ahp). Jurnal Ekonomi Dan Keuangan, 1(1), 21.

Sheila Almira, I. S. (2020). Analisis layanan Customer Service Dalam Upaya Meningkatkan Pelayanan Nasabah Pada Bank Mega Kantor Cabang Pembantu MT Haryono Balik Papan. September, 460-469.

Susanti, F., Marlius, D., Kahirumi, S. (2021). Customer Satisfication Pada Pembelian Smartphone Samsung Dilihat Dari Trust In Brand, Brand Image Dan Word Of Mouth Di Sarana Smartphone Kota Solok. Jurnal Pundi. Volume 5. No. 1. Hal. 1-20. Sekolah Tinggi Ilmu Ekonomi KBP.

Totok Budisantoso, N. (2018). Bank Dan Lembaga Keuangan Lain. Jakarta: Salemba Empat. 